\title{
Research on Inheritance of Intangible Cultural Heritage
}

\author{
Jian $\mathrm{Yi}$ \\ College of Art and Communication, Bohai University, Jinzhou, P.R. China \\ yj1976414@163.com
}

Keywords: intangible cultural heritage; characteristics; inheritance crisis; inheritance modes; inheritance strategies

\begin{abstract}
Intangible cultural heritage is the crystallization of national civilization and wisdom. The inheritance and development of the intangible cultural heritage, is not only to inherit and carry forward the traditional culture, but also enhance the national cultural soft power, enhance national pride and cohesion. It is an important way to realize the overall coordination of economic and social development. How to realize the effective inheritance of intangible cultural heritage has become the focus of the world. In order to strengthen the inheritance and protection of intangible cultural heritage, this paper analyzes the characteristics of intangible cultural heritage, and summarizes the inheritance of intangible cultural heritage. In view of the inheritance crisis of intangible cultural heritage, drawing on the advanced experience at home and abroad, referring to the previous research results, this paper puts forward the inheritance strategy of intangible cultural heritage.
\end{abstract}

\section{Introduction}

Cultural heritage, usually refers to a region, country or ethnic groups, in the history of the development process, and the spiritual wealth and material wealth inherited from generation to generation. It can be divided into tangible cultural heritage and intangible cultural heritage. The material cultural heritage is also the cultural relic, is refers to the historical precipitation, has the artistic appreciation, and has the certain scientific value historical relic or the historical relic; The intangible cultural heritage does not exist in physical form, but language, art, dance and folk intangible form. It is closely related to people's daily life, and in the nation continues or traditional cultural forms which are inherited, including oral traditions, the performing arts, customs and traditional crafts etc..

Intangible cultural heritage is the essence of national traditional culture, also the main basis to reflect the diversity of world culture and maintain the national cultural identity. In the process of globalization and modernization, the blending and collision of different cultures make the intangible cultural heritage to a certain extent, which lead to the national characteristics fade. The change of modern cultural ecology, many of the intangible cultural heritage, which is based on the agricultural civilization, has lost the survival and development environment. Faced with the problem of survival, many projects has no inheritance because no economic benefits. The inheritance and protection of intangible cultural heritage, is the need of the national culture and attach great importance to the development of society, how to realize the effective transmission of intangible cultural heritage, has become the focus of world attention.

A long history and glorious and resplendent culture, the Chinese nation has made the extremely rich intangible cultural heritage. The inheritance and development of the intangible cultural heritage, is not only to inherit and carry forward the traditional culture, but also enhance the national cultural soft power, enhance national pride and cohesion, and it is an important way to achieve economic and social comprehensive, coordinated and sustainable development. The Chinese nation has a rich tradition of protecting and inheriting outstanding cultural heritage, the protection of intangible cultural heritage, to enhance national self-confidence and pride, enhance national identity and sense of belonging, will play a positive role in promoting. 


\section{Characteristics of Intangible Cultural Heritage}

Intangible cultural heritage has the following characteristics:

(1) Inheritance. The intangible nature of knowledge determines that intangible cultural heritage must be passed on. The so-called inheritance refers to the intangible cultural heritage has the nature by the human collective, group or individual, generation after generation to enjoy, inherit or develop. Reflected in the value of the intangible cultural heritage through the dynamic process of people's behavior, depending on the specific nationality, group and individual activities, through the dynamic process of the reality of human behavior created and displayed.

(2) Intangible. Intangible cultural heritage is different from the specific forms of intangible cultural heritage. It is a kind of abstract thinking culture, exists in the mind of people, and changes with the change of the idea, such as knowledge, skills, beliefs, customs and etiquette. The inheritance of intangible cultural heritage is not through the object, but the human transmission of a kind of emotion, in a specific time and space, through the spirit of the exchange of people, to achieve the purpose of information transmission.

(3) Oral. The intangible cultural heritage mainly spread in rural areas, most of the heirs are illiterate, they can't get their mastery of the skill and custom of finishing a book, because of the inheritance of intangible cultural heritage has a lot of rules, such as "pass on by male not female", "pass on by others not their children". Many art is unique skills, often with the inheritance of death lead to " perish art" which intangible cultural added some mystery.

(4) Plasticity. Because of the oral tradition, there must be plasticity. Plasticity can change. Intangible cultural heritage of the "plasticity", in the performing arts, social customs, rituals, festivals and traditional crafts and other heritage, the performance is particularly prominent. The "plasticity" of intangible cultural heritage is also reflected in the variation and innovation of intangible cultural heritage.

(5) Popular character. Intangible culture is produced in the folk, but also mainly in the folk. Most of the intangible cultural heritage has a strong color of the people and the local flavor, through the collective adaptation and innovation of folk artists throughout the ages, passed on by the public recognition. Whether it is the origin of intangible cultural heritage or the main subject of inheritance, both with obvious public. The intangible cultural heritage originates from the people and is inherited from the people.

\section{Inheritance Crisis of Intangible Cultural Heritage}

There are many reasons for the inheritance crisis in the course of inheriting intangible cultural heritage, which mainly includes the following aspects:

(1) Impact of living environment. After the reform and opening up, the rapid development of the city, people's living environment has undergone tremendous changes, urbanization makes the existence of a large number of intangible cultural heritage has suffered a devastating impact. In the age of network society and information age, the younger generation becomes farther and farther with the traditional customs. In the vast rural areas of the intangible cultural heritage, the living environment of traditional culture has been destroyed due to the erosion of urban culture and urban life style.

(2) Heritage loss. With the increasing of the aging population, many people have inherited frail, unable to engage in related skills, and more and more young people go out to work or study, rarely in the original art in the living environment of learning and training, more and more people engaged in the inheritance of intangible cultural heritage is less, more and more non material culture heritage encounters heritage crisis, facing the danger of extinction.

(3) Over exploitation. The intangible cultural heritage protection consciousness is weak, paying attention to the declaration and development, and the protection and management of the phenomenon is more common, driven by economic interests, "materialistic" utilitarian tendency is serious. On the one hand, we must strive to squeeze into the national "heritage"; on the other hand, 
over exploitation of some cultural heritage. Predatory exploitation, destructive construction and enterprise management have become the new difficulties in the protection of intangible cultural heritage.

(4) Underinvestment. Although the Chinese government attaches great importance to the protection and utilization of intangible cultural heritage, and increased investment from the central government. But from the specific situation, the central government's investment is far from enough, the local government's investment in intangible cultural heritage protection and utilization is less. It is impossible for the economic value of intangible cultural heritage to be well developed and utilized.

(5) Lack of unified planning. The process of intangible cultural heritage in the development of economic value, because of the understanding of unity, coordination and local protectionism and other factors, the lack of overall planning and overall arrangement, often appear blind development situation. In addition, due to the cognitive value of original ecological culture superficial, tourism market of the folk art heritage of the vulgar and cheap development, resulting in the destruction of cultural and ecological misleading to the society, the lack of overall assessment of the value of national cultural resources.

(6) Laws and regulations are not perfect. It is the most stable and effective way to protect the intangible cultural heritage through legal means. The protection of intangible cultural heritage in China, although the formation of the "intangible cultural heritage law" as the center, other laws and regulations of the legal system as a supplement, but there are still many problems in the implementation process, it is not clear that the ownership of intangible cultural heritage, intangible cultural heritage of the scope of a wide range of people, the provisions of the legal responsibility is not clear.

\section{Inheritance Mode of Intangible Cultural Heritage}

The inheritance of intangible cultural heritage mainly in the following ways:

(1) The way of inheriting the people as the center. This is the way of inheritance, which has been paid much attention to, and is also the main form of intangible cultural heritage. It mainly includes two kinds: A representative of the inheritors, refers to the state agencies to identify the intangible cultural heritage at all levels of the carrier and the bearer of the intangible cultural heritage of the rich knowledge and skills. The other is the general inheritors of intangible cultural heritage in the field, in addition to the recognized representative inheritors, other non government recognized heritage, plays a fundamental and recurring role of the individual in the actual inheritance inheritance.

(2) On the basis of festival celebration. Festival celebration is not only a traditional way of inheritance, but also one of the more modern ways of inheritance in recent years. Traditional folk festivals rely on the firsthand and lasted for thousands of years, be handed down from age to age, has been relatively stable in group members inside accumulated cultural emotion, during the holiday, if you do not obey certain traditional customs, individual members will feel the feelings of loss. Some festival celebrations are intangible cultural heritage, through the festival celebration activities, but also to promote the transfer and inheritance of other intangible cultural heritage.

(3) On the way of inheritance by group. A lot of intangible cultural heritage has been created and owned by the group, which has been handed down from generation to generation, also known as "folk memory" or "collective memory". Sometimes in a cultural area, sometimes in a range of ethnic groups, a large number of social members (groups) to participate in the inheritance of the same cultural heritage, indicating that the group's common cultural psychology and beliefs. This way of inheritance of intangible cultural heritage mainly includes three categories: first, customs and manners; second, the age of the year is the order of the class; the three is a large-scale folk activities.

(4) On the way of inheritance of tourism activities. The intangible cultural heritage of tourism activities is mainly reflected in the Intangible Cultural Heritage Week, the tourism development of folk experience activities, etc.. At present, some intangible cultural heritage has gradually entered 
the mass tourism market, and shows a huge market potential, remarkable economic benefits and social effects. Through tourism activities, we can not only promote the intangible cultural heritage in the local heritage effectively, but also can make the migrant workers become a potential and recessive inheritance, the intangible cultural heritage and inter group communication.

(5) School education as the auxiliary way of transmission. The mode of inheritance of intangible cultural heritage in school education is a process of national cultural integration with human nature and rational spirit. The intangible cultural heritage in Colleges and universities has its unique advantages, such as organizing lectures on intangible cultural heritage, intangible cultural heritage into the classroom, the preparation of intangible cultural heritage and other educational activities. The intangible cultural heritage into the curriculum system, the intangible cultural heritage and teaching practice closely linked, so that school education activities in the intangible cultural heritage of the play an active role in the heritage.

\section{Inheritance Strategies of Intangible Cultural Heritage}

In order to solve the inheritance of intangible cultural heritage crisis, according to the characteristics of the intangible cultural heritage, with the inheritance of intangible cultural heritage, referring to the domestic and foreign advanced experience inheritance, with reference to previous research results, this thesis put forward the strategy of intangible cultural heritage:

(1) To realize the organic combination of the representative inheritors and the general inheritors. As the center of the subject of inheritance, not only to the representative of the heritage center, the role of the general heritage is not to be ignored. We must play the typical representative inheritors and exemplary role, but also to mobilize the enthusiasm of the general heritage, so that the majority of people to actively participate in the implementation of the normal inheritance and day-to-day work, and consciously safeguard the intangible cultural heritage. The Intangible Cultural Heritage Representative inheritors, in carrying out the inheritance activities, at the same time, combined with the general composition of inheritance inheritance, the main structure of sound, form a complete system of inheritance, which is conducive to healthy, normal and natural heritage.

(2) Strengthen the legal construction of intangible cultural heritage protection. At present, China's intangible cultural heritage protection legal system is still not perfect, it is necessary to improve the laws and regulations on the protection of intangible cultural heritage on the basis of the original law. The formulation of laws and regulations should be combined with the actual situation, and learn from the advanced experience of international cultural heritage protection, strengthen the legislative work, to achieve the cultural heritage of the legal framework of the rich and perfect. The formulation of the law needs to define the object of protection of the heritage, the responsibility of each department, and the punishment for the destruction of the inheritance act. Strengthening the legal construction of intangible cultural heritage protection can provide legal protection for intangible cultural heritage protection.

(3) Strengthen the awareness of the masses to protect intangible cultural heritage. The intangible cultural heritage is rooted in the masses, and the economically backward areas are rarely affected by the modern culture, and the intangible cultural heritage can be protected more completely. To publicize the intangible cultural heritage through many channels, to stimulate the public's attention to folk art. The intangible cultural heritage belongs to the people, and must rely on the masses. By holding art performances and seminars and other promotional activities, so that more people, especially young people understand the intangible cultural heritage, cultivate love and confidence of the intangible cultural heritage, to mobilize the enthusiasm of the intangible cultural heritage protection and inheritance.

(4) Popularization of intangible cultural heritage and protection education. From the point of view of education, strengthen the education of intangible cultural heritage, and effectively solve the problem of the lack of awareness of the protection of intangible cultural heritage. Education is an important way of human history and cultural heritage. In order to protect the intangible cultural heritage, we should define the mission and obligation of the state and the people in the protection of intangible cultural heritage in the form of legislation, the intangible cultural heritage included in the 
national education system, promote the people of the intangible cultural heritage protection from thought to change behavior, promote government and people consciously protection, inheritance and development of the intangible cultural heritage resources, and comprehensively improve the level of national quality and moral.

(5) Expanding the influence of intangible cultural heritage by means of high technology. Technology has changed the way people produce and live. The intangible cultural heritage should also meet the development needs of the times, use high-tech means to open the effective development and use, promote the value of the continuous growth, to expand its influence and visibility. The specific methods include document collation, image processing and digital protection. Document processing and image processing are recorded by means of words, sounds, pictures and images. Digital protection is the digital finishing, the use of Internet communication, the intangible cultural heritage of the results can be translated into the network to spread the virtual products.

(6) Promote the inheritance of intangible cultural heritage through industrial development. Moderate development is the best means of transmission. The intangible cultural heritage has distinct national characteristics and regional cultural connotation, contains a large number of cultural resources, and has potential economic value. Based on the inheritance and protection of the cultural industry and economic development on the hook, with value of the resources, strengthen cultural and technological innovation, production and protection, establish the ideas of industrialization development, scientific and rational positioning and planning, formulate scientific development strategy, focus on cultivating brand advantage of intangible cultural heritage, protection for the establishment of production base, the intangible cultural heritage exhibition, cultural resources event to cultural industry, give full play to the value of the intangible cultural heritage.

\section{References}

[1] L. G. Huang, "Three Inheritance Paths of Current China's Intangible Cultural Heritage," Thinking, vol. 43, no. 1, pp. 150-155, 2017.

[2] F. H. Song, Y. Liu, "The digital protection and inheritance strategy of intangible cultural heritage from the perspective of cultural industry," Shandong Social Sciences, vol. 29, no. 2, pp. 83-87, 2015.

[3] Study Times, "Group inheritance of intangible culture," http://www.china.com.cn/xxsb/txt/2007-03/06/content_7913882.htm, 2017-4-2.

[4] J. Si, "The present situation and problems of the protection of intangible cultural heritage," Journal of Yan'an Vocational \& Technical Institute, vol. 27, no. 3, pp. 11-13, 2013.

[5] J. Y. Xin, T. H. Wu, J. S. Wu, "On the legal protection of intangible cultural heritage in China," Guizhou Social Sciences, vol. 35, no. 9, pp. 82-86, 2014.

[6] W. B. Lei, "On the training strategy of Chinese Intangible Cultural Heritage," Journal of Karamay, vol. 27, no. 1, pp. 58-61, 2013. 